\title{
Behavioral interventions to improve population health outreach for hepatitis C screening: randomized clinical trial
}

\author{
Shivan J Mehta, ${ }^{1,2}$ Susan C Day, ${ }^{1}$ Anne H Norris, ${ }^{1}$ Jessica Sung, ${ }^{1,2}$ Catherine Reitz, ${ }^{1,2}$ \\ Colin Wollack, ${ }^{3}$ Christopher K Snider, ${ }^{2}$ Pamela A Shaw, ${ }^{4}$ David A Asch ${ }^{1,2,5}$
}

${ }^{1}$ Department of Medicine,

Perelman School of Medicine,

University of Pennsylvania,

Philadelphia, PA, USA

${ }^{2}$ Center for Health Care Innovation, University of

Pennsylvania, Philadelphia, PA, USA

${ }^{3}$ Information Services, Penn Medicine, University of

Pennsylvania, Philadelphia, PA, USA

${ }^{4}$ Department of Clinical Epidemiology, Biostatistics, and Informatics, University of Pennsylvania, Philadelphia, PA, USA

${ }^{5}$ Center for Health Equity Research and Promotion,

Philadelphia VA Medical Center, Philadelphia, PA, USA

Correspondence to: S I Mehta, 14-174 PCAM South Tower

3400 Civic Center Boulevard,

Philadelphia, PA, USA shivan.

mehta@pennmedicine.upenn.edu (ORCID 0000-0001-6066-4739) Additional material is published online only. To view please visit the journal online.

Cite this as: $B M J$ 2021;373:n1022 http://dx.doi.org/10.1136/bmj.n1022

Accepted: 14 April 2021

\section{ABSTRACT}

OBJECTIVE

To evaluate whether opt out framing, messaging incorporating behavioral science concepts, or electronic communication increases the uptake of hepatitis $\mathrm{C}$ virus (HCV) screening in patients born between 1945 and 1965 .

DESIGN

Pragmatic randomized controlled trial.

SETTING

43 primary care practices from one academic health system (Philadelphia, PA, USA) between April 2019 and May 2020.

PARTICIPANTS

Patients born between 1945 and 1965 with no history of screening and at least two primary care visits in the two years before the enrollment period.

\section{INTERVENTIONS}

This multilevel trial was divided into two studies. Substudy A included 1656 eligible patients of 17 primary care clinicians who were randomized in a 1:1 ratio to a mailed letter about HCV screening (letter only), or a similar letter with a laboratory order for HCV screening (letter+order). Substudy B included the remaining 19837 eligible patients followed by 417 clinicians. Active electronic patient portal users were randomized $1: 5$ to receive a mailed letter about HCV screening (letter), or an electronic patient portal message with similar content (patient portal); inactive patient portal users were mailed a letter. In a factorial design, patients in substudy B were also randomized $1: 1$ to receive standard content (usual care), or content based on principles of social norming, anticipated regret, reciprocity, and commitment (behavioral content).

MAIN OUTCOME MEASURES

Proportion of patients who completed HCV testing within four months.

\section{WHAT IS ALREADY KNOWN ON THIS TOPIC}

Hepatitis $C$ virus screening rates remain low, despite recommendations to screen patients born between 1945 and 1965

Concepts from behavioral science such as opt out framing, effort reduction, social norming, and commitment have been shown to increase healthy behavior in other contexts

\section{WHAT THIS STUDY ADDS}

Opt out framing and effort reduction by including a signed laboratory order with outreach increased screening uptake

Behaviorally informed messaging content did not increase screening uptake Mailed letters achieved a greater response rate than electronic patient portal messages

\section{RESULTS}

21303 patients were included in the intention-totreat analysis. Among the 1642 patients in substudy A, $19.2 \%$ (95\% confidence interval $16.5 \%$ to $21.9 \%$ ) completed screening in the letter only arm and $43.1 \%$ (39.7\% to $46.4 \%)$ in the letter+order arm ( $\mathrm{P}<0.001$ ). Among the 19661 patients in substudy B, $14.6 \%$ (13.9\% to $15.3 \%$ ) completed screening with usual care content and $13.6 \%$ (13.0\% to $14.3 \%)$ with behavioral science content $(P=0.06)$. Among active patient portal users, $17.8 \%$ (16.0\% to $19.5 \%)$ completed screening after receiving a letter and $13.8 \%$ (13.1\% to $14.5 \%)$ after receiving a patient portal message $(P<0.001)$.

\section{CONCLUSIONS}

Opt out framing and effort reduction by including a signed laboratory order with outreach increased screening for HCV. Behavioral science messaging content did not increase uptake, and mailed letters achieved a greater response rate than patient portal messages.

TRIAL REGISTRATION

ClinicalTrials.gov NCT03712553.

\section{Introduction}

The hepatitis C virus (HCV) has historically been the leading cause of liver transplant and hepatocellular carcinoma in the United States. ${ }^{12}$ Direct acting antivirals can result in sustained virologic response in more than $95 \%$ of those treated with minimal side effects, but the benefits of treatment are limited by several patients with undiagnosed HCV. ${ }^{34}$ National guidelines recommend HCV screening for all patients born between 1945 and 1965 because of the higher prevalence in these birth cohorts, and screening tests are covered with no cost sharing. ${ }^{56}$ Many states in the US have mandated offering HCV testing to all eligible outpatients, $^{7}$ including Pennsylvania where this study was based. ${ }^{8}$ However, screening rates in this group remain low and variable across practices, ${ }^{9-11}$ possibly because many patients do not routinely see their primary care clinician, and there could be competing priorities at appointments. Screening might be increased by complementing efforts in clinic with direct outreach to patients' homes, which has been incorporated into other population health initiatives. ${ }^{12-14}$ Electronic patient portals that allow patients to send and receive messages securely have proliferated across health systems as a low cost alternative to mailed letters for outreach.

Recent insights from behavioral science reveal that humans have predictable biases, such as status quo bias, and interventions that leverage the same biases 
can be used to promote healthy behaviors. ${ }^{15-18}$ For example, changing decisions from opt in to opt out framing can nudge patients toward preventive health activities while maintaining patient autonomy. ${ }^{19-23}$ The conventional opt in approach implies that the default is for the patient to not participate, while opt out framing suggests that the status quo is for the patients to participate in the health promoting activity. Messaging that incorporates social norms, anticipated regret, reciprocity, and commitment has increased energy conservation, cancer screening, workplace performance, and vaccination rates. ${ }^{24-28}$ Similar approaches might advance HCV screening.

We used the Pennsylvania mandate for population HCV screening as motivation to improving screening outreach by simultaneously comparing several approaches: opt out versus opt in; electronic patient portal messaging versus mailed outreach; and messaging that incorporates behavioral science principles versus standard messaging.

\section{Methods}

Study design

This was a multilevel, pragmatic, randomized clinical trial divided into two concurrent studies to evaluate behavioral interventions to increase uptake of HCV screening through outreach to patients (fig 1). In substudy A, eligible patients were randomly assigned to a traditional mailed letter signed by the primary care clinician describing the importance of and eligibility for HCV screening; or a mailed letter with similar messaging and a laboratory requisition for $\mathrm{HCV}$ antibody testing.

Substudy B was a separate, patient level randomized trial among the remaining eligible patients that used a factorial design. Among patients who used the electronic patient portal, we compared electronic communication with mailed letters. Among all patients in substudy $\mathrm{B}$, we concurrently compared standard messaging about HCV screening with messaging informed by concepts from behavioral science, such as social norming, anticipated regret, reciprocity, and commitment.

The study was approved by the institutional review board at the University of Pennsylvania. A waiver of informed consent was obtained because the study was minimal risk to patients and could not have been practicably carried out without the waiver. ${ }^{29}$ The protocol and statistical analysis plan appear as an online supplement, and the protocol was registered at ClinicalTrials.gov (NCT03712553).

\section{Study population}

We identified all patients from our electronic health records who fulfilled the following criteria: patients had at least two visits in the past two years at a primary care practice in the Philadelphia region at the University of Pennsylvania with an active primary care clinician; they were born between 1945 and 1965 and had no history of an HCV antibody test or viral load; they had no record of previously declining screening.
The practices are part of an academic health system affiliated with the University of Pennsylvania. The baseline HCV screening rate across the primary care population was $61 \%$. Because this was a pragmatic, population based study, all identified patients were included with no additional exclusions.

\section{Interventions}

The health system employed 434 primary care clinicians in the Philadelphia region, 79 of whom had 35-250 eligible patients. Because substudy A initially involved cluster randomization at the clinician level, this range was determined to minimize variability of patient panels. Those 79 clinicians were invited to participate in substudy A through electronic mail, and 17 of them agreed to participate, with a combined eligible patient panel of 1656 . The remaining 417 clinicians were included in substudy B, and informed of the study and the outreach to their patients taking place on their behalf (including the use of their electronic signature).

Patients of the 17 clinicians in substudy A were randomized to two study arms in a 1:1 allocation ratio, stratified by provider, using a computerized random number generator. Patients in arm A1 (letter only) received a mailed letter signed by their primary care clinician describing the importance of HCV screening, their eligibility for screening, and instructions to contact their clinician for an HCV screening test. Patients randomized to arm A2 (letter+laboratory order) received a mailed letter with similar messaging and a signed laboratory requisition for HCV antibody screening. Participants in this arm were directed to take the laboratory requisition to the laboratory of their choice to complete their test. Laboratory requisitions were generated through bulk ordering in the electronic health records for all patients in this arm, with a physician member of the research team as the ordering provider and the primary care provider as the authorizing clinician.

All completed test results for patients in study arm A2 were routed from the electronic health record to the primary care clinician and the study team. The study team sent letters to patients with negative results, which were electronically signed by their physician. Positive results within the $\mathrm{A} 2$ arm were sent to primary care clinicians through a message in the electronic health records so that they could help with care coordination and follow-up. Because completed test results in study arm A1 were ordered by the primary care provider, they were routed and communicated according to routine practice. We initially planned to cluster randomize at the clinician level, but changed to individual level randomization (March 2019) to gain more power. Because this intervention was mainly directed at patients' homes without the need for an office visit, we did not anticipate much contamination at the clinician level.

The remaining 417 primary care clinicians accounted for 19837 patients eligible for HCV screening, who were included in substudy B. We 


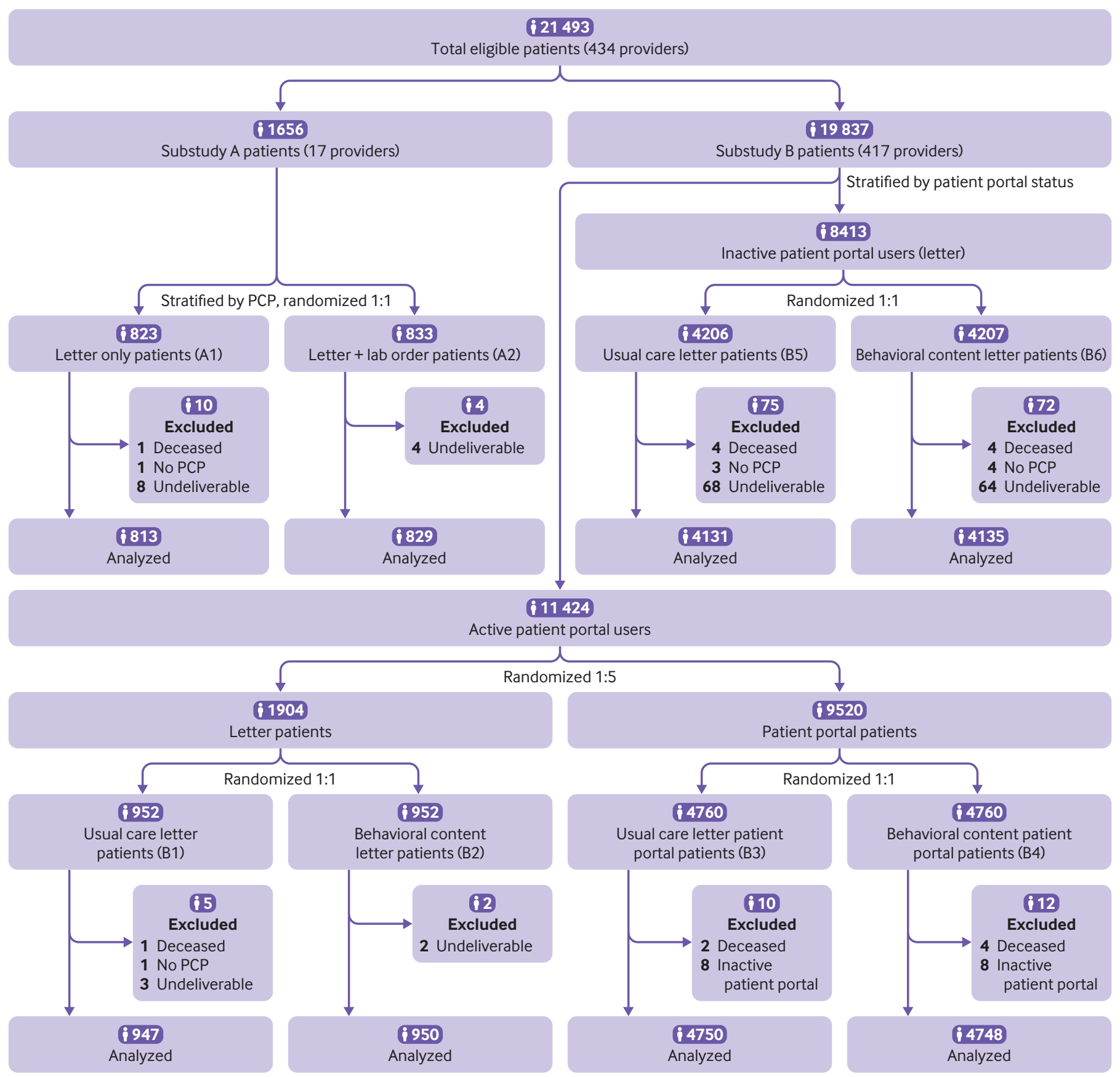

Fig 1 | CONSORT (consolidated standards of reporting trials) flow diagram. Lab=laboratory; PCP=primary care provider

identified patients as active portal users if they had read or sent at least one secure patient portal message in the previous 12 months; patients were inactive if they did not have a patient portal account or had not used their account in the previous 12 months. Fifty nine per cent of patients in the trial were active portal users and were randomized in a 1:5 allocation ratio by using a computerized random number generator to receive a mailed letter or a patient portal message. This ratio was chosen to minimize the resources needed to print and mail letters.

In a factorial design, all patients in substudy B were also randomized in a 1:1 ratio to receive standard messaging or messaging based on principles of behavioral science. Active patient portal users who were randomized to receive a mailed letter were further randomized in a 1:1 ratio to receive standard messaging (arm B1-usual care letter) or messaging based on principles of behavioral science (arm B2-behavioral content letter). Active patient portal users who were randomized to receive an electronic communication were further randomized in a 1:1 ratio to receive standard messaging (arm B3-usual care patient portal) or messaging based on principles of behavioral science (arm B4-behavioral content patient portal). Inactive patient portal users were 
randomized in a 1:1 ratio to receive a mailed letter with the standard messaging (arm B5-usual care letter) or messaging based on behavioral science (arm B6behavioral content letter). All participants in substudy B were directed to contact their primary care clinician for an HCV screening test.

Behavioral content messaging was similar to that of usual care and incorporated four concepts from behavioral economics: social norming ("Here's a chance to join the majority of others at Penn Medicine who have been screened for Hepatitis C”), anticipated regret ("We don't want you to develop liver disease that could have been prevented with earlier testing"), reciprocity ("Help us achieve our goal of having $100 \%$ of patients screened at Penn Medicine”), and commitment ("Write down a date by when you will get your screening done").

The large, population based pragmatic design allowed the testing of three hypotheses simultaneously (fig 1): opt in or opt out-a preordered test will be superior to traditional outreach (A1 $v$ A2); modeelectronic messaging will be superior to mailed outreach $(\mathrm{B} 1+\mathrm{B} 2 v \mathrm{~B} 3+\mathrm{B} 4)$; and content-messaging that incorporates behavioral science principles will be superior to standard messaging $(\mathrm{B} 1+\mathrm{B} 3+\mathrm{B} 5 v$ B2+B4+B6).

For all study arms, patients with no screening result within two months from the date of initial outreach received a reminder outreach through the same communication mode and with the same content as the initial outreach, including a copy of the laboratory requisition for patients in arm $\mathrm{A} 2$. The investigators were blinded to patient data and randomization, but the research staff were not blinded because they were administering the interventions.

\section{Study outcomes}

The primary outcome was the proportion of patients who completed HCV antibody testing within four months of initial outreach. The secondary outcome was the proportion who completed HCV antibody testing within 12 months. Additional outcomes included the proportion of HCV screening tests ordered, the proportion of tests positive, the proportion with detectable viral load, and referral rate and receipt of $\mathrm{HCV}$ treatment. Data were obtained from the electronic health records through automated data extraction and chart review if necessary for verification.

\section{Statistical analysis}

Because of the pragmatic design, our power calculations were based on the population of eligible patients in each substudy and meaningful differences to justify implementation of the interventions. We estimated that usual care messaging alone (letter only) would result in a $5 \%$ response rate based on findings from other screening outreach activities. ${ }^{2030}$ Our power calculation was based on cluster randomization, but we changed to patient level randomization before enrollment. Recruiting at least 10 clinicians with between 35 and 250 eligible patients, we estimated at least 1160 eligible patients (from preliminary data extraction). This population would provide $90 \%$ power to detect a 5 percentage point increase in response rate in the letter+laboratory order arm (A2) compared with the letter only arm (A1) using the $\chi^{2}$ test of proportions and intention-to-treat protocol, and considering a two sided $P$ value less than 0.05 as statistically significant. This increase would justify investment by a health system in sending out laboratory orders. ${ }^{31}$ For substudy B, we estimated 26162 remaining patients across the health system based on a preliminary data extraction. This population would provide approximately 90\% power to detect an increase in response rate of 0.9 percentage points for the behavioral content arms (B2+B4+B6) compared with a $5 \%$ response rate in the usual content arms (B1+B3+B5). Changing the messaging should have no additional cost, so any small increase would be important to detect. Of those remaining patients, we estimated that 15959 (61\%) would be active patient portal users. With a 1:5 randomization ratio of letter to patient portal (approximately 2659 receiving letters and 13300 receiving portal messages), we estimated approximately $90 \%$ power to detect an increase in response rate of 1.6 percentage points for the patient portal arms $(\mathrm{B} 3+\mathrm{B} 4)$ compared with the letter arms $(\mathrm{B} 1+\mathrm{B} 2)$. While this increase is modest, when applied to larger populations at scale, it would result in a large change in HCV screening uptake. We did not anticipate an interaction between messaging and mode of communication. The final number of enrolled patients was lower than prespecified estimates because of changes in screening over time and edits to the data pull to more accurately exclude patients who had already been screened for HCV.

We performed prespecified subgroup analyses for the primary outcome by patient portal user status, sex, race or ethnicity, age, and income. Race or ethnicity was based on self-reported data in the electronic health record. Household income was estimated using the American Community Survey 2013-2017 5-year estimates data for median income by zip code of residence. For the purposes of these analyses, age and income were categorized into quarters. We also tracked screening completion for the 12 month time period. All analyses were performed in Stata version 15.0 (Stata Corp, College Station, TX).

\section{Patient and public involvement}

Because this was a time sensitive health system imperative, we were not able to include patients or the public in the design, conduct, reporting, or dissemination plans of our research.

\section{Results}

\section{Patient characteristics}

A total of 21493 patients were randomized; 190 $(0.9 \%)$ were excluded mainly because of death or an inability to deliver a mailing or portal message, leaving 21303 in the intention-to-treat analysis (fig 1). The mean age was 63 years (standard deviation 6 years); $55 \%$ were women, $66 \%$ had commercial insurance, 
and $31 \%$ were insured by Medicare. About $80 \%$ of patients were white, $12 \%$ were black, and $4 \%$ were Hispanic or Latino (table 1). Median household income was \$87019 (£62680, €71920; interquartile range $\$ 68785$-97 602). The intervention was conducted from April 2019 to May 2020, when the 12 month follow-up was completed for all participants.

\section{Screening response}

At four months from initial outreach, of the 1642 patients in substudy A, 19.2\% (95\% confidence interval $16.5 \%$ to $21.9 \%$ ) completed screening in the letter only (A1) arm and 43.1\% (39.7\% to 46.4\%) in the letter+laboratory order (A2) arm (absolute difference $23.9 \%$, 95\% confidence interval $19.6 \%$ to 28.2\%, $\mathrm{P}<0.001$; table 2).

Among the 19661 patients in substudy B, 14.6\% (13.9\% to $15.3 \%$ ) completed screening with usual care content and $13.6 \%$ (13.0\% to $14.3 \%)$ with behavioral science content (absolute difference $-1.0 \%,-1.9 \%$ to $0.0 \%, \mathrm{P}=0.06)$. Among the 11395 active patient portal users in substudy B, $17.8 \%$ (16.0\% to $19.5 \%)$ completed screening after receiving letters and 13.8\% $(13.1 \%$ to $14.5 \%)$ after receiving patient portal messages (absolute difference $-4 \%,-5.8 \%$ to $-2.1 \%$; $\mathrm{P}<0.001)$. In a post hoc multivariable regression analysis among patient portal users, we found no significant interaction between letter content and mode of communication ( $\mathrm{P}=0.99)$. When accounting for two comparisons in substudy B (P value threshold of $0.05 / 2=0.025$ with Bonferroni correction), the statistical significance remained the same.

The results for the main outcomes were similar when patients were followed for 12 months after the intervention (table 3). We did not find any differences in office visits across the different comparator groups at four months (supplementary table 1). Among all patients in the study, those who had no office visits in the four months after initial outreach had a $6.3 \%$ screening rate $(691 / 11017)$ while those with one or more visits had a $25.2 \%$ screening rate $(2594 / 10286)$.

\section{Screening outcomes}

A total of $4611 \mathrm{HCV}$ antibody tests were ordered in the four month outreach period, and 3285 (15.4\%) patients received HCV antibody screening; 45 (1.4\%) were antibody positive and 14 (0.4\%) were viral load positive (table 4).

By 12 months, a total of 8649 HCV antibody tests were ordered, and 6365 (29.9\%) patients received HCV antibody screening. Of those, 87 (1.4\%) were antibody positive and 24 were found to be viral load

\begin{tabular}{|c|c|c|c|c|c|c|c|}
\hline \multirow[b]{2}{*}{$\begin{array}{l}\text { Personal } \\
\text { characteristics }\end{array}$} & \multicolumn{2}{|c|}{ Substudy A: opt in or opt out } & \multicolumn{2}{|c|}{ Substudy B: content } & \multicolumn{2}{|c|}{ Substudy B: mode } & \multirow[b]{2}{*}{$\begin{array}{l}\text { Substudy } A+B, \\
\text { all participants }\end{array}$} \\
\hline & Letter only (A1) & Letter+order (A2) & $\begin{array}{l}\text { Usual care } \\
\text { (B1, B3, B5) }\end{array}$ & $\begin{array}{l}\text { Behavioral } \\
\text { (B2, B4, B6) }\end{array}$ & $\begin{array}{l}\text { Mailed letter } \\
(\mathrm{B} 1, \mathrm{~B} 2)\end{array}$ & $\begin{array}{l}\text { Electronic portal } \\
(\mathrm{B} 3, \mathrm{~B} 4)\end{array}$ & \\
\hline No of patients & 813 & 829 & 9828 & 9833 & 1897 & 9498 & 21303 \\
\hline Age, mean (SD) & $63.1(6.1)$ & $63.1(6.3)$ & $62.8(6.1)$ & $62.7(6.0)$ & $63.0(6.0)$ & $62.9(6.0)$ & $62.8(6.0)$ \\
\hline \multicolumn{8}{|l|}{ Sex } \\
\hline Male & $348(42.8)$ & $341(41.1)$ & $4461(45.4)$ & $4476(45.5)$ & $843(44.4)$ & $4159(43.8)$ & $9626(45.2)$ \\
\hline Female & $465(57.2)$ & $488(58.9)$ & $5367(54.6)$ & $5.357(54.5)$ & $1054(55.6)$ & $5339(56.2)$ & $11677(54.8)$ \\
\hline \multicolumn{8}{|l|}{ Race } \\
\hline White & $638(78.5)$ & $657(79.3)$ & $7823(79.6)$ & $7869(78.9)$ & $1581(83.3)$ & $8003(84.3)$ & $16987(79.7)$ \\
\hline Black & $106(13.0)$ & $103(12.4)$ & $1167(11.9)$ & $1152(11.7)$ & $164(8.7)$ & $734(7.7)$ & $2528(11.9)$ \\
\hline Asian & $21(2.6)$ & $12(1.5)$ & $193(2.0)$ & $196(2.0)$ & $46(2.4)$ & $182(1.9)$ & $422(2.0)$ \\
\hline Pacific Islander & $2(0.3)$ & $2(0.2)$ & $24(0.2)$ & $23(0.2)$ & $1(0.1)$ & $13(0.1)$ & $51(0.2)$ \\
\hline American Indian & $0(0)$ & $1(0.1)$ & $7(0.1)$ & $6(0.1)$ & $1(0.1)$ & $6(0.1)$ & $14(0.1)$ \\
\hline Other & $18(2.2)$ & $26(3.1)$ & $218(2.2)$ & $225(2.3)$ & $40(2.1)$ & $203(2.1)$ & $487(2.3)$ \\
\hline Unknown & $28(3.4)$ & $28(3.4)$ & 385 (3.9) & $353(3.6)$ & $62(3.3)$ & $342(3.6)$ & $794(3.7)$ \\
\hline Refused & $0(0)$ & $0(0)$ & $11(0.1)$ & $9(0.1)$ & $2(0.1)$ & $15(0.2)$ & $20(0.1)$ \\
\hline \multicolumn{8}{|l|}{ Ethnicity } \\
\hline Hispanic or Latino & $12(1.5)$ & $7(0.8)$ & $398(4.1)$ & $406(4.1)$ & $27(1.4)$ & $121(1.3)$ & $823(3.9)$ \\
\hline $\begin{array}{l}\text { Non-Hispanic or } \\
\text { non-Latino }\end{array}$ & 787 (96.8) & $807(97.4)$ & $9352(95.2)$ & $9357(95.2)$ & $1848(97.4)$ & 9304 (98.0) & 20303 (95.3) \\
\hline Unknown & $1(0.1)$ & $1(0.1)$ & $21(0.2)$ & $23(0.2)$ & $4(0.2)$ & $22(0.2)$ & $46(0.2)$ \\
\hline Refused & $13(1.6)$ & $14(1.7)$ & $57(0.6)$ & $47(0.5)$ & $18(1.0)$ & $51(0.5)$ & $131(0.6)$ \\
\hline \multicolumn{8}{|l|}{ Portal status } \\
\hline Active & $552(67.9)$ & $547(66.0)$ & $5697(58.0)$ & $5698(58.0)$ & $1897(100 \%)$ & $9498(100 \%)$ & $12494(59)$ \\
\hline Not active & $261(32.1)$ & $282(34.0)$ & $4131(42.0)$ & $4135(42.1)$ & - & - & $8809(41)$ \\
\hline \multicolumn{8}{|l|}{ Insurance cover type } \\
\hline Commercial & $511(62.9)$ & $550(66.3)$ & $6408(65.4)$ & $6494(64.7)$ & $1264(66.6)$ & $6407(67.5)$ & $13963(65.5)$ \\
\hline Medicare & $278(34.2)$ & $257(31.0)$ & $3098(31.6)$ & $3012(30.7)$ & $603(31.8)$ & $2937(30.9)$ & $6645(31.2)$ \\
\hline Medicaid & $22(2.7)$ & $20(2.4)$ & $280(2.9)$ & $283(2.9)$ & $28(1.5)$ & $135(1.4)$ & $605(2.8)$ \\
\hline No insurance & $2(0.3)$ & $1(0.1)$ & $14(0.1)$ & $21(0.2)$ & $2(0.1)$ & $15(0.2)$ & $38(0.2)$ \\
\hline Unknown & $0(0)$ & $1(0.1)$ & $28(0.3)$ & $23(0.2)$ & $2(0.1)$ & $4(0.04)$ & $52(0.2)$ \\
\hline $\begin{array}{l}\text { Household income }(\$) \text {, } \\
\text { median }(\mathrm{IQR})^{\star}\end{array}$ & $\begin{array}{l}90683 \\
(67668-103923)\end{array}$ & $\begin{array}{l}91929 \\
(70024-103923)\end{array}$ & $\begin{array}{l}85164 \\
(68785-97452)\end{array}$ & $\begin{array}{l}87885 \\
(68785-97602)\end{array}$ & $\begin{array}{l}91929 \\
(70380-101577)\end{array}$ & $\begin{array}{l}91332 \\
(70380-101250)\end{array}$ & $\begin{array}{l}87019 \\
(68785-97602)\end{array}$ \\
\hline
\end{tabular}




\begin{tabular}{|c|c|c|c|}
\hline Substudy & $\begin{array}{l}\text { Completed antibody screening, } \\
\mathrm{n}(\% ; 95 \% \mathrm{Cl})^{*}\end{array}$ & Difference, \% (95\% Cl) & P valuet \\
\hline Letter only $(n=813)$ & $156(19.2 ; 16.5$ to 21.9$)$ & \multirow[t]{2}{*}{$23.9(19.6$ to 28.2$)$} & \multirow[t]{2}{*}{$<0.001$} \\
\hline Letter+laboratory order $(n=829)$ & $357(43.1 ; 39.7$ to 46.4$)$ & & \\
\hline \multicolumn{4}{|l|}{ Substudy B: content } \\
\hline Behavioral messaging $(n=9833)$ & $1341(13.6 ; 13.0$ to 14.3$)$ & $-1.0(-1.9$ to 0.0$)$ & 0.06 \\
\hline \multicolumn{4}{|l|}{ Substudy B: communication mode } \\
\hline Mailed letter $(n=1897)$ & $337(17.8 ; 16.0$ to 19.5$)$ & \multirow[t]{2}{*}{$-4.0(-5.8$ to -2.1$)$} & \multirow[t]{2}{*}{$<0.001$} \\
\hline Patient portal message $(n=9498)$ & $1313(13.8 ; 13.1$ to 14.5$)$ & & \\
\hline
\end{tabular}

positive. Twenty three patients $(0.4 \%)$ were referred for treatment. Based on chart review from the electronic health record, to date, 11 patients have started treatment with direct acting antiviral therapy, five have had sustained virologic response, and three have completed treatment and are awaiting final viral load testing.

\section{Subgroup analyses}

The results of the study comparisons were consistent across subgroup characteristics, including sex, age, race, and income (supplementary tables 2-4), although we were not powered to detect differences by subgroup. Black patients in substudy B showed an $11.2 \%$ increase in response to mailed letters compared with patient portal messages (supplementary table 4). In substudy B, $15.2 \%$ of active patient portal users participated in screening with usual care messaging, and $13.8 \%$ with behavioral messaging.

\section{Cost analysis}

We estimate that the cost of sending each letter was approximately $\$ 0.78$ for the printing and postage. The number needed to screen for the mailed letter compared with the patient portal message at four months was $1 / 0.04=25$ (number needed to screen=1/ absolute difference in response rate). Therefore, it costs approximately $25 \times \$ 0.78=\$ 19.50$ for each additional patient screened when sending letters. The cost of sending the laboratory slip was approximately $\$ 0.17$ in addition to the cost of mailing the letter. The number needed to screen for the laboratory slip compared with the mailed letter alone was $1 / 0.239=4.2$. Therefore, it costs approximately $4.2 \times \$ 0.17=\$ 0.71$ per additional patient screened when sending the laboratory slip.

\section{Discussion}

Principal findings

This pragmatic trial has three specific findings. Firstly, an opt out approach involving a signed laboratory order with mailed outreach doubled participation in HCV screening compared with the conventional approach of suggesting patients contact their primary care clinicians. Secondly, among active users of patient portals, mailed letters achieved a better screening response than digital communication. Thirdly, message content enhanced with principles of behavioral science did not increase screening rates. This trial also has one general finding, which is that population based health initiatives offer health systems the opportunity to rigorously test alternative approaches that might be useful elsewhere.

The simple act of sending the signed laboratory order with the mailed outreach resulted in the most dramatic increase in HCV screening. Several reasons might explain this finding. The traditional method for patient outreach is an opt in approach; patients have to actively choose to participate by contacting the primary care clinician or practice directly. Sending the signed laboratory order implies that the default is participation and eliminates the steps required for patients who want to participate but might have busy schedules; similar results have been seen in cancer screening and HIV testing. ${ }^{20-22}$ This approach is additionally facilitated by bulk ordering enabled by electronic health records, which allows a large number of orders to be signed with just a few clicks and reduces

\begin{tabular}{|c|c|c|c|}
\hline Substudy & $\begin{array}{l}\text { Completed antibody screening, } \\
\mathrm{n}(\% ; 95 \% \mathrm{Cl})^{*}\end{array}$ & Difference, $\%(95 \% \mathrm{Cl})$ & $P$ valuet \\
\hline \multicolumn{4}{|l|}{ Substudy A: opt in or opt out } \\
\hline Letter only $(n=813)$ & $279(34.3 ; 31.1$ to 37.6$)$ & \multirow[t]{2}{*}{21.9 (17.2 to 26.6) } & \multirow[t]{2}{*}{$<0.001$} \\
\hline Letter+laboratory order $(\mathrm{n}=829)$ & $466(56.2 ; 52.8$ to 59.6$)$ & & \\
\hline \multicolumn{4}{|l|}{ Substudy B: content } \\
\hline Usual care messaging $(\mathrm{n}=9828)$ & $2855(29.0 ; 28.2$ to 29.9$)$ & \multirow[t]{2}{*}{$-0.9(-2.2$ to 0.3$)$} & \multirow[t]{2}{*}{0.15} \\
\hline Behavioral messaging $(n=9833)$ & $2765(28.1 ; 27.2$ to 29.0$)$ & & \\
\hline \multicolumn{4}{|l|}{ Substudy B: communication mode } \\
\hline Mailed letter $(\mathrm{n}=1897)$ & $638(33.6 ; 31.5$ to 35.8$)$ & \multirow[t]{2}{*}{$-4.4(-6.7$ to -2.1$)$} & \multirow[t]{2}{*}{$<0.001$} \\
\hline Patient portal message $(n=9498)$ & $2778(29.3 ; 28.3$ to 30.2$)$ & & \\
\hline
\end{tabular}


the workload of primary care providers. This approach aligns with the behavioral science principle of making the best choice the easy choice. ${ }^{22} \mathrm{~A}$ randomized trial at an academic medical center in 2013 showed that repeated mailed outreach with a laboratory form and up to four mailing reminders resulted in $27 \%$ of patients being tested for HCV compared with $1 \%$ in the control group with no outreach. ${ }^{31}$

Mailed letters resulted in a 4 percentage point increase in screening response compared with electronic patient portal messaging. This result competes with the conventional approach of using electronic messages whenever feasible-an approach driven in part by lower costs but also by an intuition that those who use digital communication channels prefer them. Our results suggest that even among digital users, mailed letters are more motivating, which has been shown in other contexts. ${ }^{32} 33$ The increased response rate to mailed letters should be balanced by the higher incremental cost, which we found to be $\$ 19.50$ for each additional patient screened. Interestingly, it only cost $\$ 0.17$ per additional patient screened to add the signed order to the mailed letter. Future studies could send letters to patients who do not respond to an electronic message or could determine whether an order slip added to a patient portal message might increase uptake.

We can only speculate why the behavioral science content resulted in a similar response rate as standard messaging. Firstly, many of the behavioral science principles we included were studied in different populations and contexts. Secondly, our messaging invoked behavioral principles that have been shown to work in isolation, but their effect in combination is not clear. Thirdly, the behavioral content messages were substantially longer than the usual care content. The net result might have been distraction because previous studies have shown a reduced response rate to longer surveys. ${ }^{3435}$ Our subgroup analysis revealed that the patient portal group had a greater reduction in response for behavioral content.

Among the 3285 patients newly screened in our study, only $0.4 \%$ were viral load positive, which is lower than the $1.0 \%$ prevalence from a 2013 study. ${ }^{31}$ The lower yield could reflect the success of past efforts to encourage HCV screening among those with risk factors or the relatively affluent population of eligible patients in this study. ${ }^{36}$ The baseline HCV screening rate across our population was $61 \%$ before outreach, which is comparable to other successful interventions ${ }^{37}$ and substantially higher than national rates. Interestingly, the rate of viral load positivity among screened patients who did not have patient portal access was $1.0 \%$, suggesting this population might be at higher risk. Further research is needed for these approaches in other clinical populations. ${ }^{38}$

\section{Strengths and limitations of this study}

The strengths of this study are the prospective design and individual level randomization. This was a

\begin{tabular}{|c|c|c|c|c|c|c|c|c|c|}
\hline \multirow[b]{2}{*}{ Study arm } & \multicolumn{2}{|c|}{ Substudy A } & \multicolumn{6}{|c|}{ Substudy B } & \multirow[b]{2}{*}{ All participants } \\
\hline & $\begin{array}{l}\text { Letter only } \\
\text { (A1) }\end{array}$ & $\begin{array}{l}\text { Letter+order } \\
\text { (A2) }\end{array}$ & $\begin{array}{l}\text { UC letter } \\
\text { (B1) }\end{array}$ & $\begin{array}{l}\text { BC letter } \\
\text { (B2) }\end{array}$ & $\begin{array}{l}\text { UC portal } \\
\text { (B3) }\end{array}$ & $\begin{array}{l}\text { BC portal } \\
\text { (B4) }\end{array}$ & $\begin{array}{l}\text { UC letter } \\
\text { (B5) }\end{array}$ & $\begin{array}{l}\text { BC letter } \\
\text { (B6) }\end{array}$ & \\
\hline Total No of participants & 813 & 829 & 947 & 950 & 4750 & 4748 & 4131 & 4135 & 21303 \\
\hline $\begin{array}{l}\text { Antibody orders placed } \\
\text { at } 4 \text { months }\end{array}$ & 181 & 829 & 213 & 197 & 904 & 827 & 745 & 715 & 4611 \\
\hline $\begin{array}{l}\text { Total antibody orders } \\
\text { placed at } 12 \text { months }\end{array}$ & 333 & 829 & 404 & 401 & 1895 & 1809 & 1512 & 1466 & 8649 \\
\hline \multicolumn{10}{|c|}{ Antibody screening results at 4 months } \\
\hline Antibody negative & 154 & 353 & 174 & 161 & 683 & 616 & 550 & 547 & 3238 \\
\hline Antibody indeterminate & 0 & 0 & 0 & 0 & 1 & 1 & 0 & 0 & 2 \\
\hline Antibody positive & 2 & 4 & 1 & 1 & 7 & 5 & 15 & 10 & 45 \\
\hline $\begin{array}{l}\text { Completed antibody } \\
\text { screening at } 4 \text { months }\end{array}$ & 156 & 357 & 175 & 162 & 691 & 622 & 565 & 557 & 3285 \\
\hline Viral load positive & 0 & 0 & 0 & 0 & 0 & 3 & 6 & 5 & 14 \\
\hline \multicolumn{10}{|c|}{ Antibody screening results at 12 months } \\
\hline Total antibody negative & 277 & 461 & 320 & 313 & 1409 & 1335 & 1076 & 1080 & 6271 \\
\hline Total antibody indeterminate & 0 & 0 & 0 & 1 & 2 & 2 & 1 & 1 & 7 \\
\hline Total antibody positive & 2 & 5 & 1 & 3 & 18 & 12 & 28 & 18 & 87 \\
\hline $\begin{array}{l}\text { Total completed antibody } \\
\text { screening at } 12 \text { months }\end{array}$ & 279 & 466 & 321 & 317 & 1429 & 1349 & 1105 & 1099 & 6365 \\
\hline $\begin{array}{l}\text { Total completed any } \\
\text { screening at } 12 \text { months* }\end{array}$ & 279 & 467 & 327 & 319 & 1458 & 1372 & 1115 & 1108 & 6445 \\
\hline Total viral load pending & 0 & 0 & 0 & 0 & 3 & 0 & 0 & 0 & 3 \\
\hline Total viral load positive & 0 & 0 & 0 & 0 & 1 & 4 & 10 & 9 & 24 \\
\hline \multicolumn{10}{|l|}{ Follow-up } \\
\hline Referral made & - & - & - & - & 1 & 4 & 10 & 8 & 23 \\
\hline Started treatment† & - & - & - & - & 0 & 2 & 5 & 4 & 11 \\
\hline SVR-12 & - & - & - & - & 0 & 1 & 3 & 1 & 5 \\
\hline <12 weeks & - & - & - & - & 0 & 0 & 2 & 1 & 3 \\
\hline
\end{tabular}


pragmatic trial embedded in a naturalized clinical setting across a diverse network of primary care practices with minimal patient exclusions. A central finding of this study is that multiple important clinical research questions can be answered by embedding prospective randomization with factorial design into the day-to-day operations of a functioning health system. ${ }^{29} 39$ Additionally, the results were consistent when we followed outcomes for 12 months after the intervention.

This trial was limited to one academic health system, so the results might not be generalizable to other populations. For example, the patients who were eligible for this trial were more likely to have higher income and live in suburban areas. However, the 43 practices were diverse in patient population, geography, and practice operations. We did not find any difference in response to the interventions by sex, age, race, and income. Additionally, the end of the 12 month followup time frame coincided with the covid-19 pandemic, which could have decreased response rate. However, most of the patients screened did so early after the intervention and all arms had higher response rates than we anticipated, probably because of the attention provided by the state mandate and communication from this trial. Finally, the sample size of the study was smaller than originally anticipated, which reduced the power to detect smaller differences in screening response that might be clinically meaningful.

\section{Conclusions}

In this study, we showed how a pragmatic trial embedded in clinical operations revealed that opt out framing and effort reduction can substantially improve uptake of hepatitis $\mathrm{C}$ screening and other population health initiatives. While state mandates focus on offering screening to eligible patients, additional efforts to understand barriers to screening uptake and behavioral insights to target these barriers are needed to ensure that more patients receive testing. This focus is particularly important because guidelines are changing to recommend screening for all adults aged between 18 and $79 . .^{40}$ Future efforts could focus on a combination of more intensive outreach and reducing barriers to screening through engagement in clinic and at home. ${ }^{41-43}$

Contributors: SJM, SCD, AHN, CR, PAS, and DAA contributed to the planning of the study. SJM, SCD, AHN, JS, CR, CW, CKS, and DAA contributed to the conduct of the study. All authors contributed to the reporting of the study. SJM is responsible for the overall content as guarantor. SJM takes responsibility for the integrity of the data and the accuracy of the data analysis and the conduct of the study, had full access to all the data, and controlled the decision to publish. The corresponding author attests that all listed authors meet authorship criteria and that no others meeting the criteria have been omitted.

Funding: This trial was funded by the University of Pennsylvania Health System. SJM's time was supported by grant No K08CA234326 from the National Cancer Institute of the National Institutes of Health. The funders had no involvement in the design and conduct of the study; collection, management, analysis, and interpretation of the data; preparation, review, or approval of the manuscript; and decision to submit the manuscript for publication.

Competing interests: All authors have completed the ICMJE uniform disclosure form at www.icmje.org/coi_disclosure.pdf and declare: support from the University of Pennsylvania Health System for the submitted work; DAA owns stock in Berkshire Hathaway, is a partner in and part owner of VAL Health, and has received compensation and/ or travel support for speaking, writing, or consulting from the following organizations: Salzburg Global Seminars, GSK, JFK Health System, Cosmetic Boot Camp, Meeting Designs, Capital Consulting, Healthcare Financial Management Association, Joslin Diabetes Center, National Academy of Medicine, the Commonwealth Fund, Massachusetts Medical Society, Endocrine Society, Osteoarthritis Research Society International, Baystate Medical Center, Weill-Cornell Medical College, Association of American Medical Colleges, TED MED, National Alliance of Health Care Purchaser Coalitions, Deloitte, Harvard University, American Association for Physician Leadership, Brandeis University, University of Rochester, Partner's Health Care System, Virginia Medical Center, Johns Hopkins University, MITRE, the University of Chicago, the US Air Force and the US Space Force, the University of California; the other authors have no competing interests to disclose.

Ethical approval: The study was approved by the institutional review board at the University of Pennsylvania. A waiver of informed consent was obtained because the study was minimal risk to patients and could not have been practicably carried out without the waiver. Data sharing: No additional data available.

The lead author (SJM) affirms that the manuscript is an honest, accurate, and transparent account of the study being reported; that no important aspects of the study have been omitted; and that any discrepancies from the study as planned and registered have been explained.

Dissemination to participants and related patient and public communities: The results of this study will be disseminated across the University of Pennsylvania Health System to help guide implementation of ongoing population health strategies to increase HCV screening and other preventive health activities. The results will also be shared on the website for the Center for Health Care Innovation (https://healthcareinnovation.upenn.edu/) for broad dissemination to the public.

Provenance and peer review: Not commissioned; externally peer reviewed.

This is an Open Access article distributed in accordance with the Creative Commons Attribution Non Commercial (CC BY-NC 4.0) license, which permits others to distribute, remix, adapt, build upon this work non-commercially, and license their derivative works on different terms, provided the original work is properly cited and the use is noncommercial. See: http://creativecommons.org/licenses/by-nc/4.0/.

1 Beste LA, Leipertz SL, Green PK, Dominitz JA, Ross D, Ioannou GN. Trends in burden of cirrhosis and hepatocellular carcinoma by underlying liver disease in US veterans, 2001-2013. Gastroenterology 2015;149:1471-1482.e5, quiz e17-8. doi:10.1053/j.gastro.2015.07.056

2 de Martel C, Maucort-Boulch D, Plummer M, Franceschi S. World-wide relative contribution of hepatitis $B$ and $C$ viruses in hepatocellular carcinoma. Hepatology 2015;62:1190-200. doi:10.1002/ hep. 27969

3 Afdhal N, Zeuzem S, Kwo P, et al, ION-1 Investigators. Ledipasvir and sofosbuvir for untreated HCV genotype 1 infection. N Engl ) Med 2014;370:1889-98. doi:10.1056/NEJMoa1402454

4 Feld JJ, Jacobson IM, Hézode C, et al, ASTRAL-1 Investigators. Sofosbuvir and velpatasvir for HCV genotype 1, 2, 4, 5, and 6 infection. N Engl J Med 2015;373:2599-607. doi:10.1056/ NEIMoa1512610

5 Moyer VA, U.S. Preventive Services Task Force. Screening for hepatitis $C$ virus infection in adults: U.S. Preventive Services Task Force recommendation statement. Ann Intern Med 2013;159:349-57. doi:10.7326/0003-4819-159-5-201309030-00672

6 Smith BD, Morgan RL, Beckett GA, et al, Centers for Disease Control and Prevention. Recommendations for the identification of chronic hepatitis C virus infection among persons born during 1945-1965. MMWR Recomm Rep 2012;61(RR-4):1-32.

7 Flanigan CA, Leung SJ, Rowe KA, et al. Evaluation of the impact of mandating health care providers to offer hepatitis C virus screening to all persons born during 1945-1965 - New York, 2014. MMWR Morb Mortal Wkly Rep 2017;66:1023-6. doi:10.15585/mmwr. mm6638a3

8 Hepatitis C Screening Act” Pennsylvania General Assembly, 2016 Act 87, https://www.legis.state.pa.us/cfdocs/legis/li/uconsCheck. $\mathrm{cfm} ? \mathrm{yr}=2016 \&$ sessInd $=0$ \&act $=87$

9 Jemal A, Fedewa SA. Recent hepatitis C virus testing patterns among baby boomers. Am J Prev Med 2017;53:e31-3. doi:10.1016/j. amepre.2017.01.033

10 Kasting ML, Giuliano AR, Reich RR, et al. Hepatitis C virus screening trends: serial cross-sectional analysis of the National Health Interview 
Survey Population, 2013-2015. Cancer Epidemiol Biomarkers Prev 2018;27:503-13. doi:10.1158/1055-9965.EPI-17-0855

11 Linas BP, Hu H, Barter DM, Horberg M. Hepatitis C screening trends in a large integrated health system. Am J Med 2014;127:398-405. doi:10.1016/j.amjmed.2014.01.012

12 Levin TR, Jamieson L, Burley DA, Reyes J, Oehrli M, Caldwell C. Organized colorectal cancer screening in integrated health care systems. Epidemiol Rev 2011;33:101-10. doi:10.1093/epirev/ $\mathrm{mxrO07}$

13 Singal AG, Gupta S, Skinner CS, et al. Effect of colonoscopy outreach vs fecal immunochemical test outreach on colorectal cancer screening completion: a randomized clinical trial. JAMA 2017:318:806-15. doi:10.1001/jama.2017.11389

14 Buist DSM, Gao H, Anderson ML, et al. Breast cancer screening outreach effectiveness: Mammogram-specific reminders vs. comprehensive preventive services birthday letters. Prev Med 2017;102:49-58. doi:10.1016/j.ypmed.2017.06.028

15 Kahneman D, Knetsch JL, Thaler RH. Anomalies: the endowment effect, loss aversion, and status quo bias. J Econ Perspect 1991;5:193-206. doi:10.1257/jep.5.1.193

16 Mehta SJ, Asch DA. How to help gastroenterology patients help themselves: leveraging insights from behavioral economics. Clin Gastroenterol Hepatol 2014;12:711-4. doi:10.1016/j. cgh.2014.02.022

17 Loewenstein G, Brennan T, Volpp KG. Asymmetric paternalism to improve health behaviors. JAMA 2007;298:2415-7. doi:10.1001/ jama.298.20.2415

18 Tversky A, Kahneman D. Judgment under uncertainty: heuristics and biases. Science 1974;185:1124-31. doi:10.1126/ science.185.4157.1124

19 Chapman GB, Li M, Colby H, Yoon H. Opting in vs opting out of influenza vaccination. JAMA 2010;304:43-4. doi:10.1001/ jama.2010.892

20 Mehta SJ, Khan T, Guerra C, et al. A randomized controlled trial of opt-in versus opt-out colorectal cancer screening outreach. Am Gastroenterol 2018;113:1848-54. doi:10.1038/s41395-0180151-3

21 Mehta SJ, Troxel AB, Marcus N, et al. Participation rates with opt-out enrollment in a remote monitoring intervention for patients with myocardial infarction. JAMA Cardiol 2016;1:847-8. doi:10.1001/ jamacardio.2016.2374

22 Montoy JCC, Dow WH, Kaplan BC. Patient choice in opt-in, active choice, and opt-out HIV screening: randomized clinical trial. BMJ 2016;532:h6895. doi:10.1136/bmj.h6895

23 Halpern SD, Ubel PA, Asch DA. Harnessing the power of default options to improve health care. N Engl J Med 2007;357:1340-4. doi:10.1056/NEJMsb071595

24 Schultz PW, Nolan JM, Cialdini RB, Goldstein NJ, Griskevicius V. The constructive, destructive, and reconstructive power of social norms. Psychol Sci 2007;18:429-34. doi:10.1111/j.1467 9280.2007.01917.x

25 Kube S, Maréchal MA, Puppe C. The currency of reciprocity: gift exchange in the workplace. Am Econ Rev 2012:102:1644-62. doi:10.1257/aer.102.4.1644.

26 Schwartz J, Mochon D, Wyper L, Maroba J, Patel D, Ariely D. Healthier by precommitment. Psychol Sci 2014;25:538-46. doi:10.1177/0956797613510950

27 Milkman KL, Beshears J, Choi JJ, Laibson D, Madrian BC. Using implementation intentions prompts to enhance influenza vaccination rates. Proc Natl Acad Sci U S A 2011;108:10415-20. doi:10.1073/ pnas. 1103170108
28 Sandberg T, Conner M. A mere measurement effect for anticipated regret: impacts on cervical screening attendance. $\mathrm{Br} / \mathrm{SoC}$ Psychol 2009; 48:221-36. doi:10.1348/014466608X347001

29 Asch DA, Ziolek TA, Mehta SJ. Misdirections in informed consent - impediments to health care innovation. N Engl J Med 2017:377:1412-4. doi:10.1056/NEJMp1707991

30 Mehta SJ, Induru V, Santos D, et al. Effect of sequential or active choice for colorectal cancer screening outreach: a randomized clinical trial. JAMA Netw Open 2019;2:e1910305. doi:10.1001/ jamanetworkopen.2019.10305

31 Yartel AK, Rein DB, Brown KA, et al. Hepatitis C virus testing for case identification in persons born during 1945-1965: results from three randomized controlled trials. Hepatology 2018;67:524-33. doi:10.1002/hep.29548

32 Shih T-H, Fan X. Comparing response rates from web and mail surveys: a meta-analysis. Field Methods 2008:20:249-71. doi: $10.1177 / 1525822 \times 08317085$

33 Fowler FJJr, Cosenza C, Cripps LA, Edgman-Levitan S, Cleary PD. The effect of administration mode on CAHPS survey response rates and results: A comparison of mail and web-based approaches. Health Serv Res 2019;54:714-21. doi:10.1111/1475-6773.13109

34 Sahlqvist S, Song Y, Bull F, Adams E, Preston J, Ogilvie D, iConnect consortium. Effect of questionnaire length, personalisation and reminder type on response rate to a complex postal survey: randomised controlled trial. BMC Med Res Methodol 2011;11:62-62. doi:10.1186/1471-2288-11-62

35 Dirmaier J, Harfst T, Koch U, Schulz H. Incentives increased return rates but did not influence partial nonresponse or treatment outcome in a randomized trial. / Clin Epidemiol 2007;60:1263-70. doi:10.1016/i.jclinepi.2007.04.006

36 Omland LH, Osler M, Jepsen P, et al. Socioeconomic status in HCV infected patients - risk and prognosis. Clin Epidemiol 2013;5:163 72. doi:10.2147/CLEP.S43926

37 Balkissoon C), Hampton MD. Increasing birth cohort screening for chronic hepatitis C in a primary care clinic with panel management. / Community Health 2019;44:1055-60. doi:10.1007/s10900-019-00680-3

38 Tsay CI, Lim JK. Assessing the effectiveness of strategies in US birth cohort screening for hepatitis C infection. J Clin Transl Hepatol 2020;8:25-41. doi:10.14218/JCTH.2019.00059

39 Horwitz LI, Kuznetsova M, Jones SA. Creating a learning health system through rapid-cycle, randomized testing. $N$ Engl J Med 2019;381:1175-9. doi:10.1056/NEJMsb1900856

40 US Preventive Services Task Force. Screening for hepatitis C virus infection in adolescents and adults: US Preventive Services Task Force recommendation statement. JAMA 2020;323:970-5. doi:10.1001/jama.2020.1123

41 Yeboah-Korang A, Beig MI, Khan MQ, et al. Hepatitis C screening in commercially insured U.S. birth-cohort patients: factors associated with testing and effect of an EMR-based screening alert. / Trans/ Int Med 2018:6:82-9 doi:10.2478/itim-2018-0012

42 Kruger DL, Rein DB, Kil N, et al. Implementation of birth-cohort testing for hepatitis C virus. Health Promot Pract 2017;18:283-9. doi:10.1177/1524839916661495

43 Roberts K, Macleod J, Metcalfe C, et al. Cost effectiveness of an intervention to increase uptake of hepatitis $\mathrm{C}$ virus testing and treatment (HepCATT): cluster randomised controlled trial in primary care $B M / 2020 \cdot 368 \cdot \mathrm{m} 322-22$ doi:10.1136/bmj.m322

Web appendix: Supplement

Web appendix: Supplementary tables 